\title{
A Comparative Analysis of Traditional Methods and Communicative Language Teaching in Relation to Students' Academic and Communicative Achievement
}

\author{
Francis Setonji Yede, PhD \\ Michael Otedola College of Primary Education, Nigeria
}

Doi:10.19044/esj.2020.v16n13p134 URL:http://dx.doi.org/10.19044/esj.2020.v16n13p134

\begin{abstract}
This research is a comparative analysis of Traditional Methods and Communicative Language Teaching (CLT) and their ability to facilitate students' academic and communicative achievement at Basic Education level. Students and teachers of English as a Second Language (ESL) from secondary schools within the Badagry Local Educational District of Lagos State, Nigeria, were randomly selected and sampled as the population of the study. Remedial treatment was given to the experimental group and later, proficiency test was given to both the experimental and the control groups to measure the ability to carry out specific communicative tasks in ESL. The observation checklist and the diagnostic test (pretest) were analysed using descriptive and inferential statistics of mean, standard deviation and t-test. Data analysis revealed that the traditional method being utilised in teaching English language in L2 situations cannot promote adequate communicative competence expected of the learners of ESL at the secondary School level. The linguistic performances of the control group students in the post-tests were low and, this calls for adoption of a functional language teaching model to promote adequate communicative skills in the learners. The performance of the experimental group revealed that CLT promotes free language use and interpersonal communication skills in ESL and thereby enhances communicative competence in the learners. Teachers of ESL need to be equipped with the skills of CLT in order to achieve the goals of linguistic competence in their teaching.
\end{abstract}

Keywords: Communicative Performance, Academic Achievement, Control Group, Experimental Group, Remedial Treatment

\section{Introduction}

The strong desire for good communication skills in English, as one of the most powerful languages of the world, has brought about an increase in demand for English teaching and learning around the world and particularly 
in Nigeria. A lot of people nowadays want to develop their communicative skills in English or ensure that their children achieve accurate communicative performance in English in order to fit into the requirements of the modern world. Good platforms to learn English are provided in many ways such as through formal instruction, travel, the media and the Internet. The global yearning for communicative English has created a strong demand for quality language teaching and language learning materials and resources. In Nigeria, the main goal of English language teaching and learning is the acquisition of the skills of written and spoken English to a high level of accuracy and fluency. Fluency in English is a prerequisite for success and advancement in many fields of employment in today's world. For teachers to guide the learners to acquire the skills of written and spoken English to a high level of accuracy and fluency, high demand for a functional teaching methodology is desirable. Teaching students how to use a language is the end-product of learning the language itself. Brown (1994:77) describes the objectives of functional language teaching thus:

Beyond grammatical discourse elements in communication, we are probing the nature of social, cultural, and pragmatic features of language. We are exploring pedagogical means for 'real-life' communication in the classroom. We are trying to get our learners to develop linguistic fluency, not just the accuracy that has so consumed our historical journey. We are equipping our students with tools for generating unrehearsed language performance 'out there' when they leave the womb of our classrooms. We are concerned with how to facilitate lifelong language learning among our students, not just with the immediate classroom task. We are looking at learners as partners in a cooperative venture. And our classroom practices seek to draw on whatever intrinsically sparks learners to reach their fullest potential.

From the above, it important that language teaching and learning processes take a radical departure from the prevalent Traditional Method of Grammar Translation where the attention is wholly on rules and drills and not on what the learners can use the language to do beyond classroom and in specific socio-cultural situations. Communicative Language Teaching (CLT) consists of practical skills designed to be applied in making the teaching and learning of language meaningful and goal oriented. CLT is understood as a set of principles about the goals of language teaching, how learners learn a language, the kinds of classroom activities that best facilitate learning, and the roles of teachers and learners in the classroom. 


\section{Theoretical Framework:}

Traditional Methods

Traditional language teaching methods gave precedence to grammatical competence as the basis of language proficiency. They were anchored on the idea that grammar could be learned through direct instruction and through an approach that made much use of repetitive practice and drilling. This approach to the teaching of grammar was a deductive one: learners are presented with grammar rules and then given chance to practice using them, as opposed to an inductive approach in which students are given examples of sentences containing a grammar rule and are asked to play or experiment with them. It was assumed that language learning is meant to build up a large stock of sentences and grammatical patterns and developing ability to produce these accurately and quickly in the appropriate situation. The pattern is to establish the basic rules of the language through oral drilling and controlled practice, and then the four basic language skills were introduced, in the order of speaking, listening, reading and writing.

Techniques that were often employed included memorization of dialogs, question-and-answer practice, substitution drills, and various forms of guided speaking and writing practice. Great attention to accurate pronunciation and accurate mastery of grammar was stressed from the very early stages of language learning. The assumption behind stressing accuracy of the earlier mentioned patterns is that if students made errors, these would quickly become a permanent part of the learner's speech. Methodologies based on these assumptions include Audio-lingualism, Aural-Oral Method and Situational Language Teaching Approach. (Richards and Rodgers 2001:6465) observed that "Syllabuses based on these methods consisted of word lists and grammar lists, graded across levels."

Skehan (1996:18) commenting on the above says:

The underlying theory for traditional approaches has now been discredited. The belief that a precise focus on a particular form leads to learning and automatization - that learners will learn what is taught in the order in which it is taught - no longer carries much credibility in linguistics or psychology.

Grammar-based methodologies and accuracy activities such as drill and grammar practice, based on the notion above, have to give way to functional and skills-based teaching and to be replaced by fluency activities based on interactive small-group work. This led to the emergence of a "fluency-first" pedagogy (Brumfit 1984) in which students' grammar needs are determined on the foundation of performance of fluency tasks rather than predetermined by a grammatical syllabus. 
While grammatical competence was needed to produce grammatically correct sentences, attention shifted to the knowledge and skills needed to use grammar and other aspects of language appropriately for different communicative purposes such as making requests, giving advice, making suggestions, describing wishes and needs, and so on. What was needed in order to use language communicatively was communicative competence and this include knowing what to say and how to say it appropriately based on the situation, the participants, and their roles and intentions. Traditional teaching methods did not include information of this kind. Its assumption was that these kind communicative competence skills would be picked up unofficially.

\section{Communicative Language Teaching}

Communicative Language Teaching (CLT) as an approach to teaching foreign languages places emphasis on interaction as a means of language learning. It is generally referred to as Communicative Approach to teaching foreign languages. CLT is aimed at task based language learning approach that is targeted at language learning in active communicative situations. Great emphasis is placed on helping student to use the target language in a variety of contexts and situations.

CLT focuses on helping learners to create meaning in a situation of foreign language learning. Thus CLT aims at foreign language learning in terms of how successful a learner has developed their communicative performance skills and competence which can simply be measured through the linguistic and pragmatic abilities of the language user in both formal and sociolinguistic language use situations.

CLT is usually seen as a broad approach to teaching. Nunans (1991) identifies five features of CLT as the practice that:

i. Emphasizes learning to communicate through interaction in the target

ii. language,

iii. Introduces authentic text into learning situations

iv. Provides opportunity for learners to focus, not only on language but also on the learning management process.

v. Enhances the learners' personal experiences as important contributing element to classroom learning,

vi. Attempts to link classroom language learning with language activities outside the classroom.

The five features above focus on the learners and their achievements in employing language to perform specific communicative tasks for self actualization and social interaction (August and Shanahan 2009, Yule 1995, Savignon 1985). It is also a series of activities that connect between language taught in the classroom and the language used outside the classroom. Any language teaching activity, therefore, that helps students develop their 
communicative competence in the context and situation of use should be encouraged as an acceptable and beneficial form of instruction.

CLT in the light of the above is the involvement of the learners in a series of linguistic activities leading to communicative performance and discovery learning. This is achieved through focus on real conversations, performance of linguistic tasks and replicating situations. A situational conditioned linguistic behavior ultimately leads to achievement of communication which is the end product of language use.

Berns (1984:5) says "language is interaction; it is interpersonal activity and has a clear relationship with society". In this light, language pedagogy has to look at the function of language in contexts: its social or situational contexts - the speakers, their social roles and the mode of discourse.

\section{Statement of Problem}

It is generally believed that performances of students at both primary and secondary levels are becoming lower both in ability to express oneself orally and in writing. So many students, in Nigeria, nowadays find it difficult to express themselves in passable English both in oral and in written forms and this has led to a high percentage of failure in English Language papers at the Basic Education level and even at the Senior Secondary School Certificate Examination level. The case has degenerated to such a level that students and parents cut corners in order to excel in this crucial subject. To capture this unfavorable situation, Akere (1995:195) says; "The primary school leaver, apart from the product of a few elite private schools does not possess the required competence in the four language skills for both cognitive and communicative functions."

It is noted from above that the level of linguistic competence and performance of average/ majority schools age students is dismally low. The language education scholars linked this phenomenon to the inability of the teachers to apply the right methods and skills in handling the various aspects of English in order to realize the goals of its teaching. The inability to realize the main goal of teaching English Language in Nigerian schools has led to the conclusion that the majority of English Language teachers in Nigeria lack appropriate finesse to handle basic areas of English Language to a successful end. Ubahakwe (1988) concluded that "Nigerian English Language teachers are not thoroughly grounded in content and methodology"

The issue of methodology is a complex one. There are divergent views among the Language educationists about this issue. While some blame the problem on the abandonment of traditional grammar, others argue that variety of such as grammar translation, audio lingual, silent etc confuse teachers and students and thus, students fail woefully to learn English functionally or pass 
English Language in public examinations. (Ubahakwe and Obi, 1997; Oluikpe, 1979; Adeyanju, 1989; Mohammed,1995).

It was observed from the above that teachers of English as a Second Language (ESL) in Nigeria lack adequate knowledge of appropriate methods that will enhance communicative competence and desirable academic achievement among primary and secondary school students in Nigeria. It is pertinent to compare the traditional methods and communicative language teaching method and, to assess the strength and ability of the techniques of CLT in achieving desired goals of communicative competence in ESL teachers' instructional efforts.

\section{Objectives of the Study}

Our primary aim in this study is to compare the traditional methods and CLT and, to inquire into the extent and ability of the techniques of CLT in achieving desired goals of communicative performance and competence in English language teachers' instructional efforts. This study foregrounds the role of CLT and also draws attention of the teachers to the needs of improving their methods of teaching and to encourage functional teaching and learning of English language in Nigerian schools. The specific objectives of the study are, therefore, to:

1. determine the proficiency level of students in both spoken and written English.

2. serve as remedy for structural problems detected in linguistic performance of the students.

3. assess the effect of the remedial treatment on the student's linguistic performance in both spoken and written English.

4. determine the influence of adopting communicative language teaching methods on the student's linguistic performance.

\section{Research Hypothesis}

H1. There will not be a significant difference in the linguistic performance of the students taught English Language with traditional method and the student taught with CLT.

HQ. There will be a significant difference in the linguistic performance of the student taught English Language with traditional method and the students taught with CLT.

\section{Methodology}

This study adopted randomized control group pretest and post-test quasi-experimental research design. Pretest involved using WAEC/NECO standardized instruments to determine the proficiency level of students in both spoken and written English. The treatment was structured to serve as remedy 
for structural problems detected in linguistic performance of the students. Posttest was used to assess the effect of the remedial treatment given. Comparative analysis of results was also done to determine the influence of CLT on the student's linguistic performance.

The subject consists of 300 students that were randomly selected from two (6) schools out of 30 secondary schools in Badagry Local Educational Districts of Lagos State. Two (2) Senior Secondary School II Classes in each of the schools were used for the experimental and control group study repectively. The instruments for the study were Verbal Ability Test validated for Nigerian Students by Obemeata (1976), Ajiboye (1996) and Jiboku (1998). Its use in this study was meant to classify the subjects into high and low proficient in spoken and written English for the purpose of data analysis.

Written Achievement Test was constructed by the researcher for the purpose of the present study. The instruments were validated through pilot test. They were also subjected to content, face and construct validity with reliability coefficient of $0.77,0.81$ AND 0.78 for the three tests included in the overall test instruments. The tasks in the tests demanded the students to write short essays, stories and letters of different formats to assess communicative ability through choice of vocabularies to reflex appropriate situations and register and also to assess grammatical accuracy of the students. The study was carried out for 10 weeks in the schools selected.

\section{Instrument for Data Analysis}

The data collected were analyzed using descriptive and inferential statistics of Mean, Standard deviation and t-test.

\section{Procedures for Data Analysis}

The scores of the achievement test were dully collated and critically compared with one another so as to get the correlation and differences in the students' linguistic achievement. The teacher questionnaire was also analysed based on the cluster of items that dwell on the research hypothesis. Meanwhile, all the questionnaire returned were carefully checked to ensure that they were properly completed. Pearson's Product Moment Correlation and chi-square statistical method were used to determine the differences in response and also, the effectiveness of the CLT based on student performance.

Statistical analysis of pre-test

The t-value was 1.094 with hypothesis tested as:

Ho $=: \mathrm{u}=\mathrm{o}$ (no difference)

$\mathrm{Ha}=: \varnothing=\varnothing$ (there is difference)

The analysis of pre-test shows that there will be no difference in the performance of the students if given new treatment and if the population mean 
is $=0$. The assumption here is that student may put up a better performance if they are taught with CLT method. This is indicated in ' $\mathrm{t}$ 'cal being less than ' $\mathrm{t}$ ' tab $(1.094<1.96)$ at $95 \%$ confidence interval or 0.05 significance level.

\section{Statistical analysis of post-test result (using T-Test)}

The t-test value was 4.673 with 78 degree of freedom.

The decision rule was:

If $\mathrm{Ct}<\mathrm{E} \sqrt{ }$ the result is statistically significant at $95 \%$ confidence interval or 0.05 significance level. Of 1.96

\section{$1.96<4.673$}

This analysis shows that't' cal was found to be 4.67 while the value of t' tab was found to be 1.96 at 0.05 significance level. This shows that the critical value 1.96 is less than the empirical value 4.67. The decision rule is that alternative hypothesis would hold. This means that at $95 \%$ confidence interval, the student taught and treated with CLT performed better compared with the students in the control group who were being taught with the other methods of L2 teaching i.e. Grammar translation method. It clearly shows that there is statistical significant difference between the two groups (control group and experimental group). Also, it was observed that the standard deviation and the mean deviation of the sample of the two groups are significantly different.

Analysis of Experimental Group Score

\begin{tabular}{|l|l|l|}
\hline Score & F & Percentages \\
\hline $0-3$ & 4 & 2.50 \\
\hline $4-7$ & 142 & 95.00 \\
\hline $8-10$ & 4 & 2.50 \\
\hline Total & $\mathbf{1 5 0}$ & $\mathbf{1 0 0}$ \\
\hline
\end{tabular}

This table shows that the majority of students taught with CLT scored between 4- 7 representing 95\% of the total population of the students used for the experimental study while the students scoring between 0-3 and 8-10 represent $2.5 \%$ each. This shows an improvement in the performance got from pre-test as indicated above.

Analysis of Control Group Score

\begin{tabular}{|l|l|l|}
\hline Score & F & Percentages \\
\hline $0-3$ & 75 & 50.00 \\
\hline $4-7$ & 75 & 50.00 \\
\hline $8-10$ & 00 & 0.00 \\
\hline Total & $\mathbf{1 5 0}$ & $\mathbf{1 0 0}$ \\
\hline
\end{tabular}

This table reveals that $50 \%$ each of the students' score between $0-3$ and 4-7 while nobody could obtain a mark above 7 . Under close observation, 
there is an indication of improvement in the performance of the subject in the control group. This could be caused by some unidentified variables such as shift in the method of teaching used by the teacher or through the association of the students in the experimental group with those in control group.

The major conclusion to be drawn from the comparison of the performance of the two groups is that of a major statistical significant difference in the communicative performance between the two groups. Students in the experimental group scored above 7 marks while no students in the control group scored above 7 marks.

\section{Discussion of Findings}

In the course of the study, it was discovered that the traditional methods being utilised in teaching English Language in L2 Situations cannot promote adequate communicative competence expected of the learners of English Language at the secondary School level. This problem was intoned in the findings of Crawford, 2014; Akere, 1995; and Adejare 1995. All of them lament lack of coordination and communication in the type of English language skills being acquired at both primary and secondary levels and which eventually have negative effect on the academic performances at the institutions of higher learning in ESL situations.

It should be noted that educational failure is a linguistic failure. The analysis of posttest result shows that the null hypothesis was rejected. Here the linguistic performances of the student in the tests were low. This necessitated adoption of the alternative hypothesis that clearly shows that students will put up a better performance if they are taught with CLT. After the careful testing of the hypothesis, " $t$ " cal is less than " $t$ " tab $(1.094<1.96)$ at $95 \%$ confidence interval or 0.005 significant levels. This finding agrees with those Schleppegrel and Colombi , 2002; Mohan,2017; Yede ,2003 and carrel, 1983 which calls for a more functional language teaching models and methods to promote communicative performance in the learners of English as second language.

Moreover, it was also discovered that teachers of English in L2 situations lack the knowledge of varieties of CLT teaching skills needed to bring about vigour and smooth communication abilities in second language classrooms. This findings falls in line with those of (Beckett and Slatter,2005; Crystal 2001; Martin and Rose,2007) which clearly base the improper teaching of English Language on lack of finesse from the teachers. Methods are used to develop three important aspects of teaching and learning a second language; these are cognitive, affective and psychomotor skills. For a teacher to teach a second language effectively and efficiently, he needs to be equipped with multifarious skills of CLT in order to achieve the best in his teaching. This view was validated by the findings in table 4.4 where the students in the 
experimental group performed better in using the target language (English) to express situational occurrences and contextual issues fluently. This breakthrough occurred as a result of the adoption of CLT skills. This result substantiates those of (Echevaria, Short and Power, 2006) which call for the use of functional and effective language teaching methods to achieve better instructional target.

The findings therefore reveal that the use of CLT promotes free language use and interpersonal communication skills in L2 and thereby enhances communicative competence in L2 learners. Furthermore, communicative performance and competence, which is the aim of language teaching and learning, targets the discourse aspects that enhance the ability to use language in meaningful communication beyond sentence level. In the word of Savignon (1983:27) "Discourse competence is concerned not with the interpretation of isolated sentence but with the connection of a series of sentences and utterances to form a meaningful whole." To buttress our point on the usefulness of CLT in language teaching, the experimental group performed better using vast array of non-linguistic and paralinguistic strategies to express themselves adequately within the limit of the context of interaction. It was also shown through data analysis and the testing of the research hypothesis that students will perform better in using English language for interpersonal and socio-cultural purpose if they are taught through the CLT. The test of hypothesis reveals that ' $t$ ' cal is less than ' $t$ ' tab $(1.094<$ 1.96) at $95 \%$ Confidence interval or at 0.05 significance level.

\section{Conclusion}

Remedial drill, situational drill and dialogue drill embedded in CLT skills are effective means of promoting and enhancing communicative performance which is the target of second language teaching. This will promote national and international intelligibility in the use of English among the learners. These skills enhance proper and effective performances in the use of L2 for inter personal and socio cultural purposes. Classroom activities that involve the use of dialogue, role play and oral practice should be encouraged against the normal practice of teaching L2 through chalkboard and textbooks. Situational and contextual language use should be encouraged and practised in classroom situations through systematic selection of topics involving dayto-day activities.

Finally, CLT is targeted at achieving communication. Nevertheless, communication is task oriented. To achieve functional competence in the target language, therefore, there must be performances of specific tasks. Thus, classroom activities must be directed towards performance of specific language skills acquisition. Yule, 1982 and Dutcher, 2004 give examples of such tasks such as: 
1. Story telling task: distinguishing characters, events and location in the story being narrated.

2. Instructional task: This involves giving instruction by the speaker and the hearer acting on the instruction through clarity and apt detail in the instruction.

3. Assembly task: This is the use of instruction to make the hearer carry out or put some components together. This is known as information transfer. It is aimed at making learners acquire skills through specific instruction.

\section{References:}

1. Adejare, O. (1995) communicative competence in English as a second language. In A Bamgbose, A. Banjo \& A Thomas (Eds.), New Englishes a west African perspective (pp. 153-177) Ibadan: The British Council.

2. Adeyanju, T.K. (1989). English in the JSS Curriculum: Its subject, medium and practical functions. The State of the art. Nigeria Educational Forum, 12(1)59-70.

3. Ajiboye, J. (1996). A self-learning programme, the modified lecture method, and student's cognitive and effective outcome in some population education concepts: - Unpublished Doctoral dissertation, University of Ibadan, Ibadan.

4. Akere, F. (1995). Teaching pronunciation and speaking skills. In M. Jibril, J.I Macaulay, B.O. Ikeguchi, B.A Adelola \& C. Ukwuegbu (Eds). Handbook for Junior Secondary School English Language Teachers (pp. 65-68). Lagos: Nigerian Educational Research and Development.

5. August, D. \& Shanahan, T. (2006). Developing literacy in second language learners: Report of the National Literacy Panel on Language Minority Children and Youth. Mahwah, NJ: Lawrence Erlbaum Publishers \& Center for Applied Linguistics.

6. Beckett, G. and Slater T. (2005) The Project Framework: a tool for language, content, and skills integration. ELT Journal, 59, 108-116.

7. Carrel, P. (1986). A view of the written text as communicative interaction: implication for reading in a second Language. In Devine et al, 1986.

8. Calderón, M. and Minaya-Rowe, L. (2003) Designing and implementing two-way bilingual programs: A step by step guide for administrators, teachers, and parents. Thousand Oaks, CA: Corwin Press.

9. Close, R.A. (1965). Correctness, Rule and Explanation. In H.B. Allen (Ed), Teaching English as a second language (PP. 257-265). New York: Macgraw-Hill Book Company. 
10. Crawford, J. (2014). Educating English learners: Language diversity in the classroom. Los Angeles: Bilingual Education Services, Inc.

11. Dutcher, N. (2004) Expanding educational opportunity in linguistically diverse societies. Washington, DC: Center for Applied Linguistics.

12. Echevarria, J. Short, D. and Powers, K. (2006) School reform and standards-based education: An instructional model for English language learners. Journal of Educational Research, 99 (4), 195-210

13. Gibbons, P. (2003) Mediating language learning: Teacher interactions with ESL students in a content-based classroom. TESOL Quarterly, 27(2), 247-273.

14. Janzen, J. (2008) Teaching English language learners in the contentareas. Review of Educational Research, 78 (4), 1010-1038.

15. Jiboku, A. (1998) The relative effectiveness of critical reading and semantic mapping instructional strategies on Secondary School Student' learning outcome in Reading comprehensions unpublished Ph.D thesis, University of Ibadan, Ibadan.

16. Mohan, B. (2017). Knowledge structures in social practices. In J. Cummins \& C. Davison (Eds.), The international handbook of English language teaching (pp 303-316). New York: Springer.

17. National Policy on Education Federal Republic of Nigeria (1981), (Revised) Lagos: Federal Government Press.

18. Obemeata, J. (1976). The influence of first language on verbal intelligence test: Unpublished Ph.D. dissertation, University of Ibadan.

19. Oluikpe, B.O. (1979). Can a knowledge of Grammar make us better writers? In Ubahakwu (Ed). The Teaching of English Studies (PP. 4656) Ibadan: Ibadan University Press.

20. Richards, J., and Theodore R. (2001). Approaches and Methods in Language Teaching. Second Edition. New York: Cambridge University Press.

21. Schleppegrell, M. and Colombi, M. (Eds.) (2002). Developing advanced literacy in first and second languages. Mahwah, NJ: Erlbaum.

22. Savignon, S. (1983). Communicative Competence Theory and Classroom Practice Reaching, M. A: Addison-Wesley Publishing Company.

23. Ubahakwe, E. (1988). Towards a Harmonised ELT Programme in Nigeria. Journal of English as a Second Language. (PP. 64-79).

24. Yede, F. (2003), Evaluation of Language Teaching Methods and their Effects on Students' Achievement in Senior Secondary Schools. Unpublished M.ED thesis, Lagos State University, Ojo, Lagos. 